\title{
Magnolol-Loaded Core-Shell Hydrogel Nanoparticles: Drug Release, Intracellular Uptake, and Controlled Cytotoxicity for the Inhibition of Migration of Vascular Smooth Muscle Cells
}

\author{
Yen-Jen Wang, ${ }^{\dagger}$ Yin-Chih Chien, ${ }^{\dagger}$ Chieh-Hsi Wu, ${ }^{\dagger}$ and Dean-Mo Liu, ${ }^{*}$ \\ ${ }^{\dagger}$ Nano-Bioengineering Laboratory, Department of Materials Science and Engineering, National Chiao Tung University, Hsinchu 300, \\ Taiwan \\ ${ }^{\ddagger}$ Department of Pharmacology, China Medical University, Taichung 404, Taiwan
}

\begin{abstract}
Encapsulation and release behavior of a waterinsoluble drug, magnolol, using a core-shell polysaccharidebased nanoparticle, manipulating the cellular internalization and controlled cytotoxic effect of magnolol-loaded nanoparticles over the A10 vascular smooth muscle cells (VSMCs) was reported. A magnolol-polyvinylpyrrolidone (PVP) core phase was prepared, followed encapsulating by an amphiphilic carboxymethyl-hexanoyl chitosan (CHC) shell to form a magnololloaded core-shell hydrogel nanoparticles (termed magnolol$\mathrm{CHC}$ nanoparticles). The resulting magnolol-CHC nanoparticles were employed for evaluation of drug release and controlled

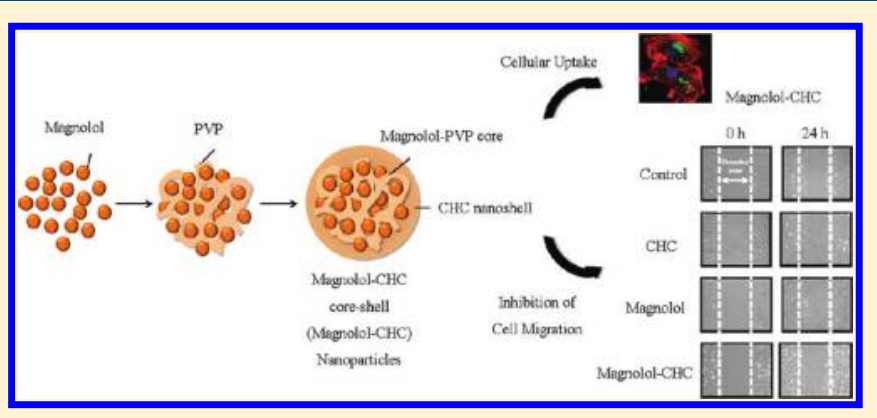
cytotoxic inhibition of VSMCs migration in vitro. A sustained release of the magnolol from the nanoparticles was determined. The magnolol-CHC nanoparticles exhibited outstanding cellular uptake efficiency, and under a cytotoxic evaluation, an increased antiproliferative effect and effective inhibition of VSMC migration as a result of efficient intracellular delivery of the encapsulated magnolol in comparison to free magnolol was achieved. We then envision a potential intracellular medication strategy with improved biological and therapeutic efficacy using the magnolol-CHC nanoparticles illustrated in this work.
\end{abstract}

KEYWORDS: core-shell hydrogel nanoparticle, magnolol-CHC nanoparticle, cell migration inhibition, cell uptake, magnolol, intracellular delivery

\section{INTRODUCTION}

With the explosive advancement of biomaterials technologies for nanoparticle synthesis, particulate nano-objects developed for drug delivery have been receiving widest attention over the years. ${ }^{1}$ Nanoparticles with designed architectures including layer-by-layer, core-shell, and self-assembled micellar nanostructure have been employed to carry drugs of diverse physiochemical properties for targeted medications. ${ }^{2-4}$ Except for recent technical modifications upon drug carriers with functions including targeting, imaging, and/or diagnosis, ${ }^{5,6}$ one of the major and practically important goals of using such a nanoparticle carrier is to increase the bioavailability and solubility of most hydrophobic drugs and reduce unwanted toxicity to patients after medication. However, it is more interesting to examine controlled cytotoxicity for a highly potent drug via the design of biocompatible particulate drug nanocarriers.

In this study, we employed magnolol as a model molecule. Magnolol, a hydroxylated biphenol compound isolated from the herb 'Houpo' (Magnolia officinalis), has been widely used in the treatment of a number of diseases in traditional Chinese medicine due to its outstanding properties such as antioxidant, ${ }^{7-9}$ antiinflammatory, ${ }^{10,11}$ anticancer, ${ }^{12,13}$ antidepressant ${ }^{14}$ and inhibited proliferation of vascular smooth muscle cell (VSMCs). ${ }^{15,16}$ Recent evidence suggests that magnolol is a highly pleiotropic molecule that interacts physically with its diverse range of molecular targets including transcription factors, growth factors and their cytokines, enzymes, and genes regulating cell proliferation and apoptosis. ${ }^{17-22}$

With increasing attention toward the inflammatory process in injured arterial wall over the recent past decade, it has been well recognized that a great extent of migration and exaggerated proliferation of VSMCs in the lumen predominates the narrowing of the injured artery. ${ }^{23}$ Earlier studies have shown that pretreatment with antioxidants can significantly reduce balloon injury-induced neointima formation. ${ }^{24,25}$ Therefore, it is expected that strong antioxidant drugs such as magnolol, having antioxidant activity approximately 1,000 times greater than $\alpha$ tocopherol, ${ }^{26}$ should play a crucial role in preventing balloon injury-induced migration of VSMCs along the injured artery wall. Despite extensive research and development on magnolol-based investigations, relatively poor solubility of magnolol, being highly hydrophobic in nature, in aqueous solution remains a major hurdle over its bioavailability and clinical efficacy. However, many Chinese medicinal material extracts have poor solubility

Received: May 16, 2011

Accepted: September 15, 2011

Revised: September 5, 2011

Published: September 26, 2011 
or slow dissolution rate, which may reduce tissue absorption and therapeutic potency upon administration. ${ }^{27}$

With these therapeutic inadequacies, many efforts have been made to design new drug carrier systems that are able to improve the drug's solubility and stability in vivo, while retaining its therapeutic efficacy. To increase its solubility and bioavailability, attempts have been made through encapsulation using liposomes ${ }^{28}$ and cyclodextrin. ${ }^{27}$ Traditional liposomal drug carriers are limited by low drug encapsulation efficiency, poor storage stability, rapid clearance from the bloodstream, nonspecific uptake by the mononuclear phagocytic system, poor control over release of the drug from the liposome and rapid drug loss profiles in vivo. ${ }^{29,30}$ Thus, colloidal drug carriers based on biodegradable polymers have received great attention recently for local release of drug toward the arterial wall. ${ }^{29,31}$ Among polymeric nanoparticulate materials, hydrogel nanoparticles have been the point of convergence of a considerable amount of effort devoted to the study of these systems dealing with drug delivery approaches. It seems that a vast range of biomedical sectors, from pharmaceutics to clinical practices, will benefit from the hydrophilicity, flexibility, versatility, high water absorptivity, and biocompatibility of these particles and all the advantages of the nanoparticles themselves, mainly long life span in circulation and the possibility of being actively or passively targeted to the diseased sites. $^{32}$

Different methods have been adopted to prepare hydrogel nanoparticles. Besides the commonly used synthetic polymers, active research is focused on the preparation of nanoparticles using naturally occurring hydrophilic polymers. ${ }^{33}$ Extensive attempts have been made using hydrogels to achieve ideal drug delivery systems with desirable therapeutic features. ${ }^{34}$ The unique attractive physicochemical and biological characteristics of hydrogels, along with their huge diversity, collectively, have led to considerable attention to these polymeric materials as excellent candidates for delivery systems of therapeutic agents. $^{34,35}$

Chitosan, one of the most plentiful biomaterials prepared from $\mathrm{N}$-deacetylation of chitin, has attracted significant interest in biotechnology fields because of its well-known low toxicity, excellent biocompatibility and biodegradability. ${ }^{35}$ In this study, a core-shell nanoparticle with a structural arrangement of drugpolyvinylpyrrolidone (PVP) core and chitosan shell was designed. The shell was virtually constructed using a new type of amphiphilic chitosan-based hydrogel, i.e., carboxymethyl-hexanoyl chitosan (CHC). The CHC was, as reported earlier from this lab, modified first by hydrophilic carboxymethylation to increase the flexibility of the chitosan molecule in aqueous solutions followed by hydrophobic modification with hexanoyl moieties along the amino groups of the chitosan to render the resulting chitosan more amphiphilic in character. ${ }^{36}$ Previous study confirmed the cytocompatibility of the $\mathrm{CHC}$ with respect to both normal and cancerous cell lines; its colloidal stability and structural integrity together with the self-assembling capability of the $\mathrm{CHC}$ made it a potential carrier for either hydrophilic or lipophilic agents with high encapsulation efficiency. ${ }^{37}$ Study on magnolol encapsulation and subsequent release behavior was performed in vitro; release kinetics was determined in order to better understand the release mechanism from the core-shell nanocarrier and its potential correlation with cellular migration behavior.

To determine the cellular uptake pathway, cells were preincubated with specific inhibitors of caveolae formation, ${ }^{38}$ clathrin association, ${ }^{39}$ and F-actin polymerization ${ }^{40}$ to block several endocytic pathways. Intracellular distribution of the core-shell nanoparticles was further evaluated after cellular uptake, and in the meantime, intracellular drug distribution was accordingly determined along with the uptake pathway using confocal microscopy. The magnolol-loaded core-shell hydrogel nanoparticle (magnololCHC nanoparticles) can be a promising intracellular drug delivery vehicle through a specific endocytosis pathway to efficiently inhibit the migration of VSMCs.

\section{MATERIALS AND METHODS}

Chitosan $\left(M_{\mathrm{w}}=215000 \mathrm{~g} / \mathrm{mol}\right.$, deacetylation degree $=$ 85-90\%) was supplied from Aldrich-Sigma. 3-(4,5-Dimethylthiazol-2-yl)-2,5-diphenyltetrazolium bromide (MTT), 4',6-diamidino-2-phenylindole (DAPI), 2-propanol, sodium hydroxide, chloroacetic acid, polyvinylpyrrolidone ( 29,000 MW), fluorescein isothiocyanate (FITC), phosphate buffered saline (PBS), cytochalasin D (CytD), chlorpromazine (CPZ), genistein and hexanoyl anhydride were purchased from Sigma. Magnolol was purchased from Wako (Wako, Japan). All other chemical reagents in the study were analytical grade and used as received without further purification.

Preparation and Characterization of Magnolol-Loaded Core-Shell Nanoparticles. The core phase of the nanoparticles was prepared by the emulsification solvent diffusion method. ${ }^{41}$ The concentrations and the volume of the core phase were optimally selected after preliminary experiments, in order to achieve final core composition of the nanoparticles. Magnolol (v/v 5\%) and polyvinylpyrrolidone, PVP (v/v 10\%), were first dissolved in $1 \mathrm{~mL}$ of methanol. The resulting solution was injected into an aqueous solution $(1 \mathrm{~mL})$, followed by vigorous agitation forming an emulsion phase. Methanol was then removed under reduced pressure using a rotary vacuum evaporator at room temperature, and the emulsified phase was then filtered through a $1.0 \mathrm{~mm}$ cellulose ester Millipore filter to separate agglomerates from the solution. The final volume of the magnolol core phase was adjusted to $1 \mathrm{~mL}$ with distilled water, followed by adding a predetermined amount of the amphiphilic chitosan ( $\mathrm{CHC}$ ) at ambient to form a self-assembled shell phase, resulting in a final nanocarrier with a structural configuration of magnololPVP core and CHC shell, hereinafter termed magnolol-CHC nanoparticles. After dialysis for 2 days, the solution was centrifuged at $10000 \mathrm{~g}$ for $30 \mathrm{~min}$ to remove free magnolol. The supernatant was filtered with a $0.8 \mu \mathrm{m}$ syringe filter and lyophilized to give a white powder. The morphological shapes of the magnolol-CHC nanoparticles were confirmed using transmission electron microscopy (TEM) (JEOL 2100, Japan) and scanning electron microscopy (SEM) (S6500, JEOL, Japan). Each sample $(1 \mathrm{mg} / \mathrm{mL}$ in distilled water) was placed on a 300-mesh copper grid coated with carbon. After drying of the sample, negative staining was performed using a droplet of $2 \mathrm{wt} \%$ uranyl acetate. An aliquot amount of the nanoparticle suspension was placed on a silicon substrate and dried under vacuum for $24 \mathrm{~h}$, and the samples were coated with a gold layer for the SEM examination.

The zeta potential and size of the nanoparticles were determined by laser Doppler anemometry (Beckman Coulter, Inc., USA). All analyses were performed on samples appropriately diluted with PBS buffer in order to maintain a constant ionic strength.

Determination of Loading Efficiency. The loading efficiency of magnolol in the magnolol-CHC nanoparticles was measured 
by high-performance liquid chromatography (HPLC). Lyophilized magnolol-CHC nanoparticles $(1 \mathrm{mg})$ were dissolved in $1 \mathrm{~mL}$ amounts of methnol to obtain clear solutions. Then, drug concentration was quantified by HPLC, based on a standard concentration curve of free magnolol in methanol. Isocratic reversed-phase HPLC was performed using a 1200 series HPLC system (Agilent Technologies, Wilmington, DE) with C18 column (Zorbax Eclipse, $5 \mu, 4.6 \times 150 \mathrm{~mm}$ ). The mobile phase consisted of 53:47 (v/v) acetonitrile/0.1\% o-phosphoric acid $(\mathrm{pH} 3.0)$ and was delivered at a flow rate of $1.0 \mathrm{~mL} / \mathrm{min}$. Eluted compounds were detected at $290 \mathrm{~nm}$ using a Spectra100 UV-vis detector.

The drug-loading efficiency (DLE, \%) was calculated with the following equations:

$$
\operatorname{DLE}(\%)=\frac{\text { amount of magnolol in nanoparticles }}{\text { amount of magnolol used for nanoparticle preparation }} \times 100
$$

In Vitro Release Study. To determine the release profile of magnolol from the magnolol-CHC nanoparticles, the dispersed nanoparticles $(1 \mathrm{mg} / \mathrm{mL})$ were placed in a SnakeSkin dialysis membrane tube $(10,000 \mathrm{MWCO})$ and the tube was immersed in $2 \mathrm{~mL}$ of PBS containing $0.1 \%$ Tween- 80 and gently shaken at $37^{\circ} \mathrm{C}$ in an orbital shaker incubator at $100 \mathrm{rpm}$. The presence of Tween- 80 assured the maintenance of sink conditions throughout the experiment due to a continuous extraction from the aqueous phase of the free magnolol dissociated from the complex and diffused through the dialysis membrane. At the predetermined time intervals, medium was withdrawn and then drug concentration was determined by HPLC. An equivalent amount of fresh medium was added to maintain a constant dissolution volume. The minimum concentration detected was $10^{-6} \mathrm{~g} / \mathrm{mL}$.

Release Kinetics. Data obtained from in vitro release profiles (with CHC concentrations of 0.5 and $1 \mathrm{mg} / \mathrm{mL}$, respectively) were fitted to various kinetic equations including first-order model, Higuchi model, and Korsmeyer-Peppas model, ${ }^{42}$ in order to find an appropriate in vitro model for theoretical consideration.

Cytotoxicity Assay. A10 vascular smooth muscle cells (VSMCs) from Food Industry Research and Development Institute (Hsinchu, Taiwan) were cultured in DMEM supplemented with $10 \%$ fetal bovine serum and $1 \%$ antibiotic antimycotic solution (Gibco, USA) in a humidified atmosphere containing $5 \% \mathrm{CO}_{2}$ in air at $37^{\circ} \mathrm{C}$.

The investigation of cell viability is a common method to evaluate the biocompatibility of biomaterials. The cytotoxicity of drug-free nanoparticles, free magnolol and magnolol-CHC nanoparticles was evaluated using VSMCs by MTT colorimetric procedure. VSMCs were plated at $2 \times 10^{4}$ cells per well in a 24 well culture plate (Corning, USA) for $24 \mathrm{~h}$ to attach, followed by replacement of the sample solutions and incubation for a predetermined time. At a predetermined time, the medium containing samples was aspirated and the wells were washed twice using PBS solution. Then, MTT solution $(0.5 \mathrm{mg} / \mathrm{mL})$ was added and incubated for $4 \mathrm{~h}$. The purple formazan was solubilized with isopropanol and measured in a microplate reader (GDV model DV 990 BV4, Italy) at $595 \mathrm{~nm}$.

Wound Healing Assay. Cell motility was examined by wound migration assay. ${ }^{43,44}$ VSMCs were cultured in a 24 -well culture plate, and the cell monolayers were wounded by scraping in a straight line with a plastic pipet tip. After washing with phosphate-buffered saline to remove nonadherent cells, cells were treated with samples for $24 \mathrm{~h}$. At the end point, migration was evaluated by counting the number of cells in the denuded zone.
Photographs were taken under phase contrast light microscopy (Nikon). Cell migration $=$ (the number of cells in the denuded zone at $0 \mathrm{~h} /$ the number of cells in the denuded zone at $24 \mathrm{~h}$ ) $\times 100 \%$.

Cellular Uptake. A flow cytometer was employed to determine the internalization of FITC-CHC nanoparticles and FITCmagnolol-CHC nanoparticles with the VSMCs; exponential growth of VSMCs was carried out. VSMCs were plated at $5 \times$ $10^{5}$ cells in a $10 \mathrm{~cm}$ dish and allowed to attach for $24 \mathrm{~h}$. The culture medium was discarded, and the cells were washed with PBS. To examine the effects of time, the cells were incubated with FITC-CHC nanoparticles and FITC-magnolol-CHC nanoparticles for predetermined time periods at $37{ }^{\circ} \mathrm{C}$, in order to determine the time-dependent cellular uptake of the nanoparticles. After the cellular uptake treatment, VSMCs were washed twice with PBS and then harvested by trypsinization. Then, VSMCs were centrifuged, collected and dehydrated with $70 \%$ ethanol overnight at $-20{ }^{\circ} \mathrm{C}$, followed by resuspending with PBS. To avoid cell aggregation, the cell solutions were filtered through a nylon membrane (BD Biosciences, USA). The cellular uptake of nanoparticles was determined by BD FACSCalibur flow cytometry, and the fluorescence intensity was quantified by CellQuest software CellQuest Pro software (BD Biosciences, USA).

In order to investigate the cellular uptake mechanism of FITC$\mathrm{CHC}$ nanoparticles and FITC-magnolol-CHC nanoparticles, VSMCs were pretreated for $30 \mathrm{~min}$ at $37^{\circ} \mathrm{C}$ with cytochalasin $\mathrm{D}(\mathrm{CytD}, 5 \mu \mathrm{M})$, chlorpromazine $(\mathrm{CPZ}, 10 \mu \mathrm{M})$ and genistein $(150 \mu \mathrm{M})$. Then the cells were incubated with the FITC-CHC nanoparticles or FITC-magnolol-CHC nanoparticles containing each inhibitor for $1 \mathrm{~h}$ at $37^{\circ} \mathrm{C}$. Following the above procedures, the cells were washed twice with PBS, detached with trypsin, resuspended, and collected for flow cytometry analysis. The mean fluorescence intensity of 10,000 individual cells was determined.

Fluorescence Confocal Microscopy. VSMCs were cultured on coverslips and incubated with or without FITC-magnolol$\mathrm{CHC}$ nanoparticles at a concentration of $15 \mu \mathrm{g} / \mathrm{mL}$ for predetermined time periods. After incubation, VSMCs were fixed with $3.7 \%$ formaldehyde and permeabilized with $0.1 \%$ Triton $\mathrm{X}-100$. Cells were subsequently washed twice with PBS and incubated at room temperature with rhodamine-phalloidin overnight. After washing with PBS, cells were stained with DAPI for $1 \mathrm{~h}$. Finally, coverslips were then mounted on glass slides by mounting solution (Dako) and observed by fluorescence confocal microscopy with a Nikon C1 Plus confocal system.

\section{RESULTS}

Characterization of the Magnolol-CHC Nanoparticles. To effectively reduce the tendency of particle agglomeration and improve the dissolution properties of the drug, PVP, which is commonly used in a variety of pharmaceutical formulations due to its low toxicity and chemical stability, was employed in this work, according to Sekikawa et al., ${ }^{45}$ who pointed out that PVP may inhibit the crystallization of drug due to interaction between drug and PVP. On this basis, enhanced magnolol dissolution is expected to be achieved as a result of poor crystallization, thus, with potentially improved bioavailability.

The resulting magnolol-CHC nanoparticles exhibited a negative zeta potential. There was no significant difference in zeta potential with different drug loads. The loading efficiency of magnolol into the nanoparticles was determined by varying loading amounts of magnolol while the $\mathrm{CHC}$ was kept constant. 
Table 1. Characterizations of Magnolol-CHC Nanoparticles ${ }^{a}$

\begin{tabular}{ccccc} 
sample & $\begin{array}{c}\text { loading amt } \\
\text { of magnolol } \\
(\mathrm{mg} / \mathrm{mL})\end{array}$ & $\begin{array}{c}\text { loading } \\
\text { efficiency } \\
(\%)\end{array}$ & $\begin{array}{c}\text { zeta } \\
\text { potential } \\
(\mathrm{mV})\end{array}$ & $\begin{array}{c}\text { size }(\mathrm{nm}) \\
\text { (polydispersity } \\
\text { index })\end{array}$ \\
magnolol(0.05)-CHC & 0.05 & $91.6 \pm 0.4$ & $-18.33 \pm 1.75$ & $235.1(0.26)$ \\
magnolol(0.1)-CHC & 0.1 & $88.4 \pm 2.3$ & $-21.22 \pm 0.72$ & $259.5(0.28)$ \\
magnolol(0.2)-CHC & 0.2 & $79.3 \pm 2.2$ & $-27.63 \pm 1.07$ & $419(0.18)$ \\
${ }^{a}$ Values are expressed as mean $\pm \mathrm{SD}(n=3)$. & \\
\hline
\end{tabular}

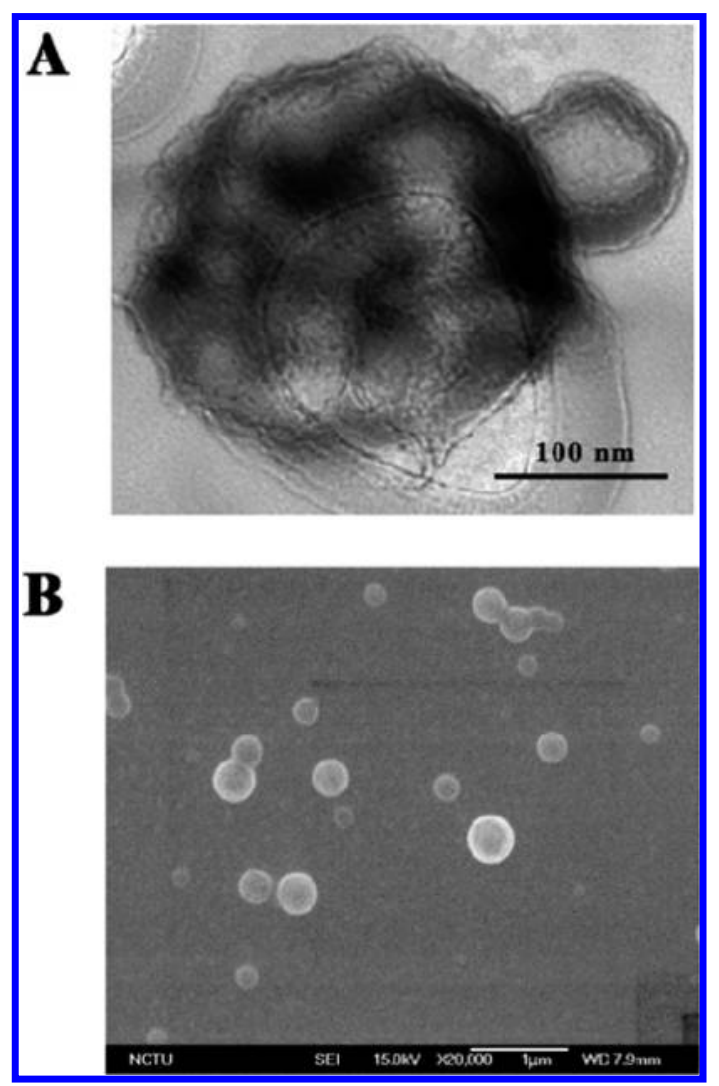

Figure 1. TEM images of magnolol-CHC nanoparticles (A) and SEM image of magnolol-CHC nanoparticles (B).

Drug loading characteristics of the nanoparticles are summarized in Table 1. The drug loading efficiency was determined ranging from $91.6 \% \pm 0.4 \%$ to $79.3 \% \pm 2.2 \%$ depending upon the starting magnolol concentration from $0.05 \mathrm{mg} / \mathrm{mL}$ to $0.2 \mathrm{mg} / \mathrm{mL}$, respectively. This finding provides a promising operation window for practical drug encapsulation over a range of the magnolol concentrations under current investigation. Structural morphology of the magnolol-CHC nanoparticles is illustrated in Figure 1, where the resulting nanoparticles are nearly spherical in shape with a relatively small amount of aggregation, and the TEM pictures revealed the two phases (a dark core area and a white shell area) indicating a core-shell structure. Meanwhile, largersized nanoparticles with multiple cores were also detected among numerous single-core particles.

In Vitro Drug Release. Figure 2A shows the release profiles of the magnolol-CHC nanoparticles (drug load of $0.2 \mathrm{mg} / \mathrm{mL}$ ) in PBS ( $\mathrm{pH} \mathrm{7.4,} 37^{\circ} \mathrm{C}$ ), wherein the nanoparticles were prepared with starting $\mathrm{CHC}$ contents of $0 \mathrm{mg} / \mathrm{mL}$ (free magnolol), $0.5 \mathrm{mg} / \mathrm{mL}$, and $1 \mathrm{mg} / \mathrm{mL}$. It demonstrates that the free magnolol

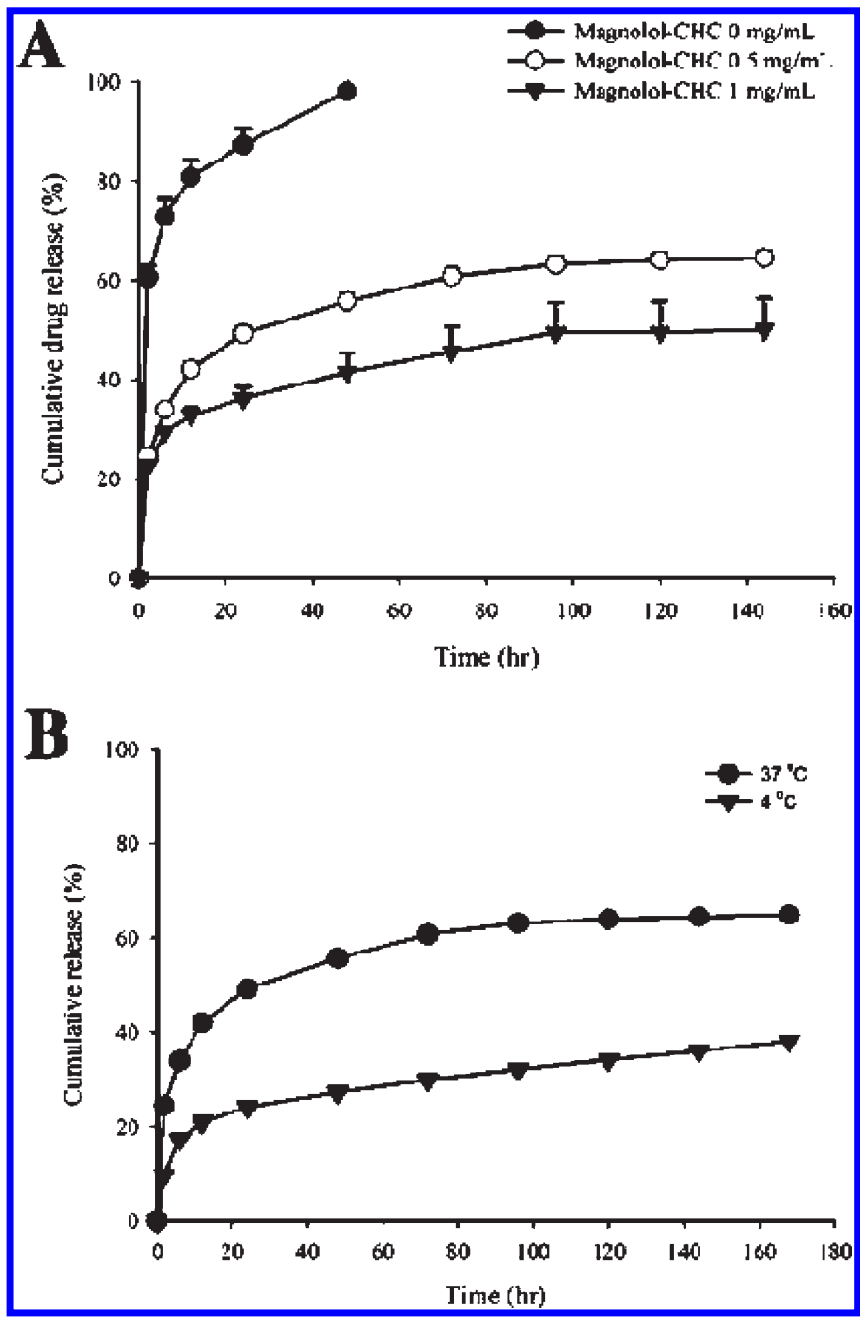

Figure 2. In vitro magnolol release profiles from magnolol-CHC nanoparticles with the different feed ratio of $\mathrm{CHC}$ (magnolol-CHC 0 $\mathrm{mg} / \mathrm{mL}$, magnolol-CHC $0.5 \mathrm{mg} / \mathrm{mL}$, and magnolol-CHC $1 \mathrm{mg} / \mathrm{mL}$ ) in PBS ( $\left.\mathrm{pH} 7.4,37^{\circ} \mathrm{C}\right)(\mathrm{A})$. Temperature-dependent release profiles of magnolol-CHC nanoparticles at $\mathrm{pH} 7.4$ measured at 37 and $4{ }^{\circ} \mathrm{C}(\mathrm{B})$. The release profiles of magnolol-CHC nanoparticles were measured by absorption at $290 \mathrm{~nm}$ with HPLC. Each data point is represented as mean $\pm \mathrm{SD}(n=3)$.

depleted in about $48 \mathrm{~h}$, where no sign of cumulative amount was further detected after $48 \mathrm{~h}$ of the eluting test. However, once being well encapsulated in the nanoparticles, much slower release profiles were detected and the release kinetics turned out to be slower as a higher amount of $\mathrm{CHC}$ was employed for the encapsulation, i.e,. reaching $\sim 45 \%$ of release for $\mathrm{CHC}$ of $1.0 \mathrm{mg} / \mathrm{mL}$, compared to $\sim 60 \%$ for $\mathrm{CHC}$ of $0.5 \mathrm{mg} / \mathrm{mL}$ over a period of 7 days. However, a burstlike release of $\sim 22-25 \%$ was observed for the first $2 \mathrm{~h}$ of both compositions of the magnolol$\mathrm{CHC}$ nanoparticles, following a steady-state profile for the rest of the 7 days. The release profile was also reduced considerably at lower eluting temperature $\left(4^{\circ} \mathrm{C}\right)$, e.g., a cumulative percentage release of magnolol decreased from $\sim 60 \%$ at $37{ }^{\circ} \mathrm{C}$ to $38 \%$ at $4{ }^{\circ} \mathrm{C}$ for a time period of 7 days, Figure $2 \mathrm{~B}$, which suggests a potential use for long-term storage of a suspension-type dosage form.

In Vitro Cytotoxicity. The cytotoxicity of the $\mathrm{CHC}$, free magnolol and magnolol-CHC nanoparticles toward VSMCs was evaluated by the MTT assay. The CHC nanoparticles 


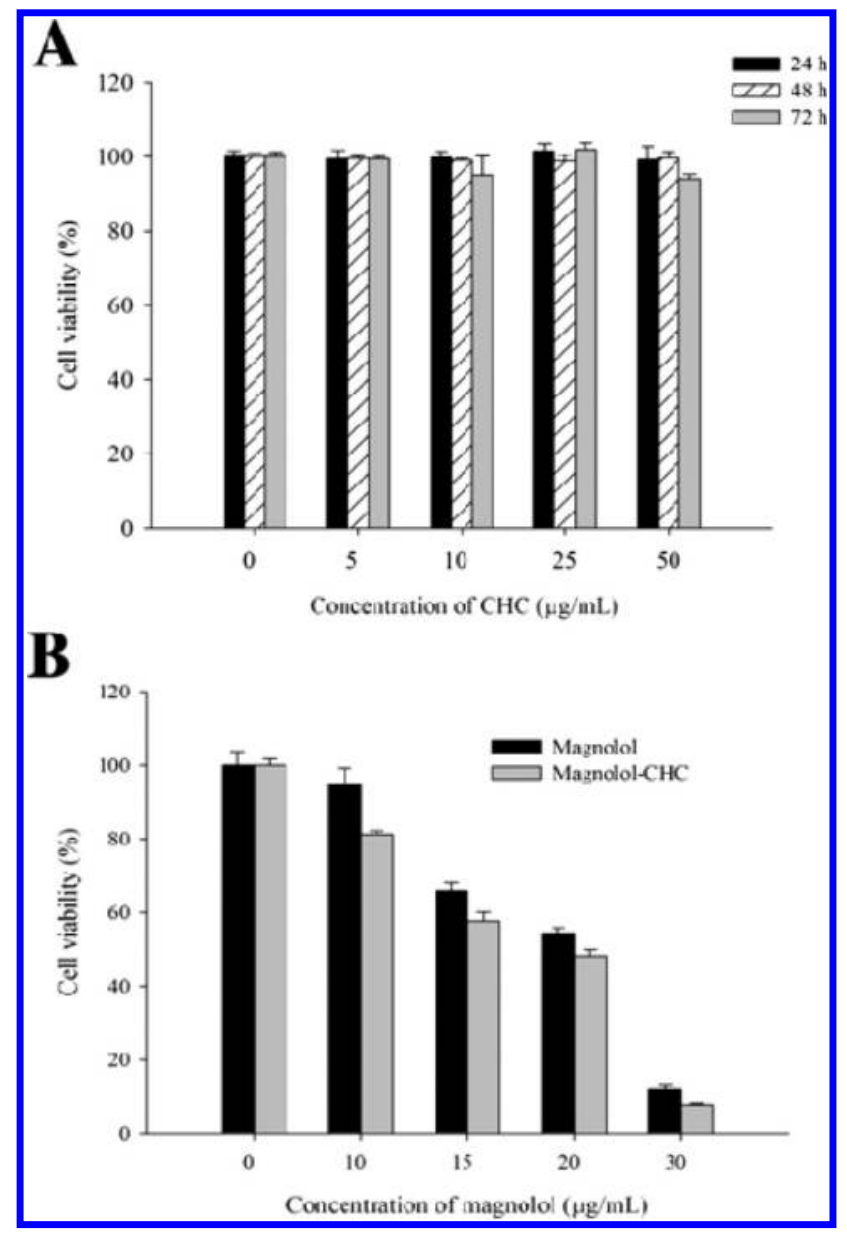

Figure 3. In vitro cytotoxicity toward VSMCs of CHC for $24 \mathrm{~h}, 48 \mathrm{~h}$ and $72 \mathrm{~h} \mathrm{(A)} \mathrm{and} \mathrm{magnolol} \mathrm{and} \mathrm{magnolol-CHC} \mathrm{nanoparticles} \mathrm{(B)} \mathrm{in} \mathrm{a}$ $24 \mathrm{~h}$ incubation was evaluated by MTT assay $(n=3)$.

(in a concentration range of $5-50 \mu \mathrm{g} / \mathrm{mL}$ ) were incubated with VSMCs for $24 \mathrm{~h}, 48 \mathrm{~h}$ and $72 \mathrm{~h}$. Cell viability remained above 94\%, indicating that the $\mathrm{CHC}$ nanoparticles were relatively biocompatible with VSMCs (Figure 3A). This observation also proves the outstanding compatibility of the polysaccharide-based polymer in drug delivery application, even though the chitosan employed has been chemically modified.

Cytotoxicity of free magnolol and magnolol-CHC nanoparticles of various concentrations with respect to VSMCs is given in Figure 3B. VSMCs were incubated with the magnolol-CHC nanoparticles at an equivalent dose to the free magnolol. Free magnolol significantly decreased the viability of VSMCs in a dose-dependent manner while the magnolol-CHC nanoparticles also inhibited the growth of VSMCs at a predicted concentration. Based on the dose-dependent controlled cytotoxic profiles, the inhibition concentration $\mathrm{IC}_{50}$ was calculated for the free magnolol and the magnolol-CHC nanoparticles, giving a value of 20.0 and $17.8 \mu \mathrm{g} / \mathrm{mL}$, respectively, indicating an improved potency for the encapsulated magnolol.

Inhibition of Cell Migration. In order to investigate the antimetastatic effect in VSMCs, a wound-healing assay was used. As shown in a representative experimental outcome in Figure 4A, by treating with free magnolol and magnolol-CHC nanoparticles (with a controlled dose of $15 \mu \mathrm{g} / \mathrm{mL}$ magnolol, a level lower than the $\mathrm{IC}_{50}$ dose) for $24 \mathrm{~h}$, the migration of VSMCs was significantly

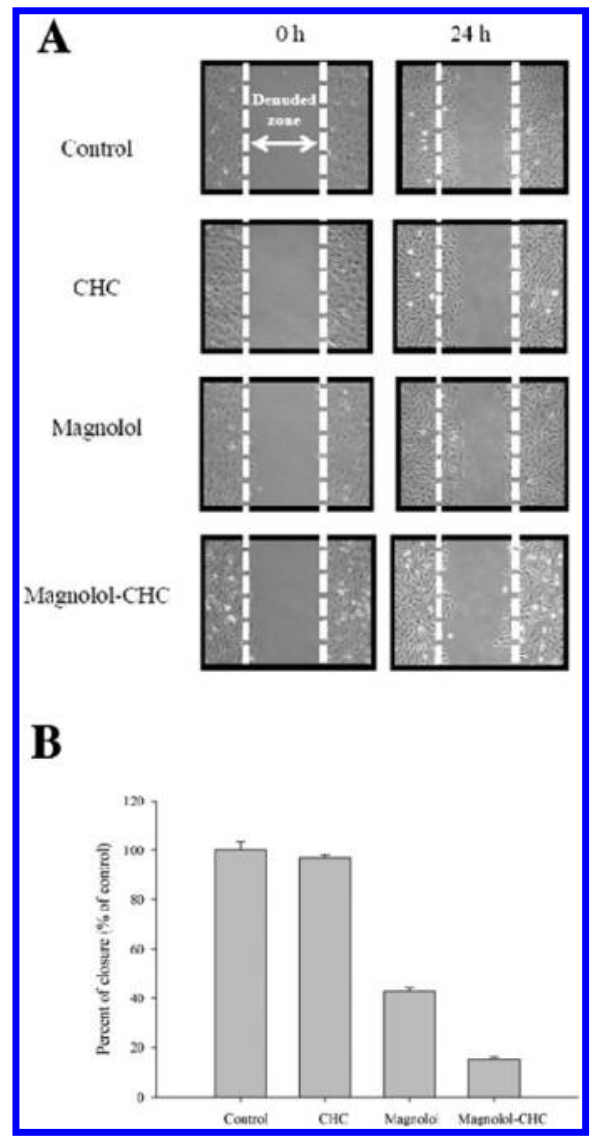

Figure 4. Inhibitory effect of $\mathrm{CHC}$, magnolol $(15 \mu \mathrm{g} / \mathrm{mL})$ and magnolol-CHC nanoparticles $(15 \mu \mathrm{g} / \mathrm{mL})$ on cell migration of VSMCs. Cell migration was examined at 0 and $24 \mathrm{~h}$ after treatment by wound healing (A). Quantitative assessment of the percent of closure according to the mean number cells in the denuded zone (B). Each data point is represented as mean $\pm \mathrm{SD}(n=3)$.

retarded as shown by the delayed wound closure. Analysis was performed by cell number in the denuded zone. Figure $4 \mathrm{~B}$ indicates that the magnolol-CHC nanoparticles illustrated a greater inhibitory effect on cell mobility (84\%) after $24 \mathrm{~h}$ incubation than free magnolol $(57 \%)$ at the same dose $(15 \mu \mathrm{g} / \mathrm{mL})$. However, $\mathrm{CHC}$ itself exerted a negligible effect on the migration of VSMCs compared to the control group.

Cellular Uptake Behavior. Through FITC labeling, endocytosis of the magnolol-CHC nanoparticles entrapped into VSMCs was further monitored by confocal microscopy to characterize the intracellular dynamics. The fluorescence images are displayed in Figure 5A. The merged image was the overlapping image obtained by DAPI channel (blue, nuclei); rhodamine channel (red, F-actin) and FITC channel (green, nanoparticles). Green fluorescence spectrum was observed inside the VSMCs after $4 \mathrm{~h}$ incubation with an equivalent dose of the magnolol-CHC nanoparticles $(15 \mu \mathrm{g} / \mathrm{mL})$. Magnolol-CHC nanoparticles were clearly observed inside the cells as green dots. This observation confirmed that the FITC-doped magnolol-CHC nanoparticles were internalized by VSMCs within $2 \mathrm{~h}$ of incubation, appearing in a punctate pattern around the nuclei, indicating that the magnolol-CHC nanoparticles were largely and efficiently taken by the cells. Furthermore, $Z$-series images revealed that the FITC-doped nanoparticles were mainly distributed within the cytoplasm (Figure 5B). The magnolol-CHC nanoparticles exhibited 


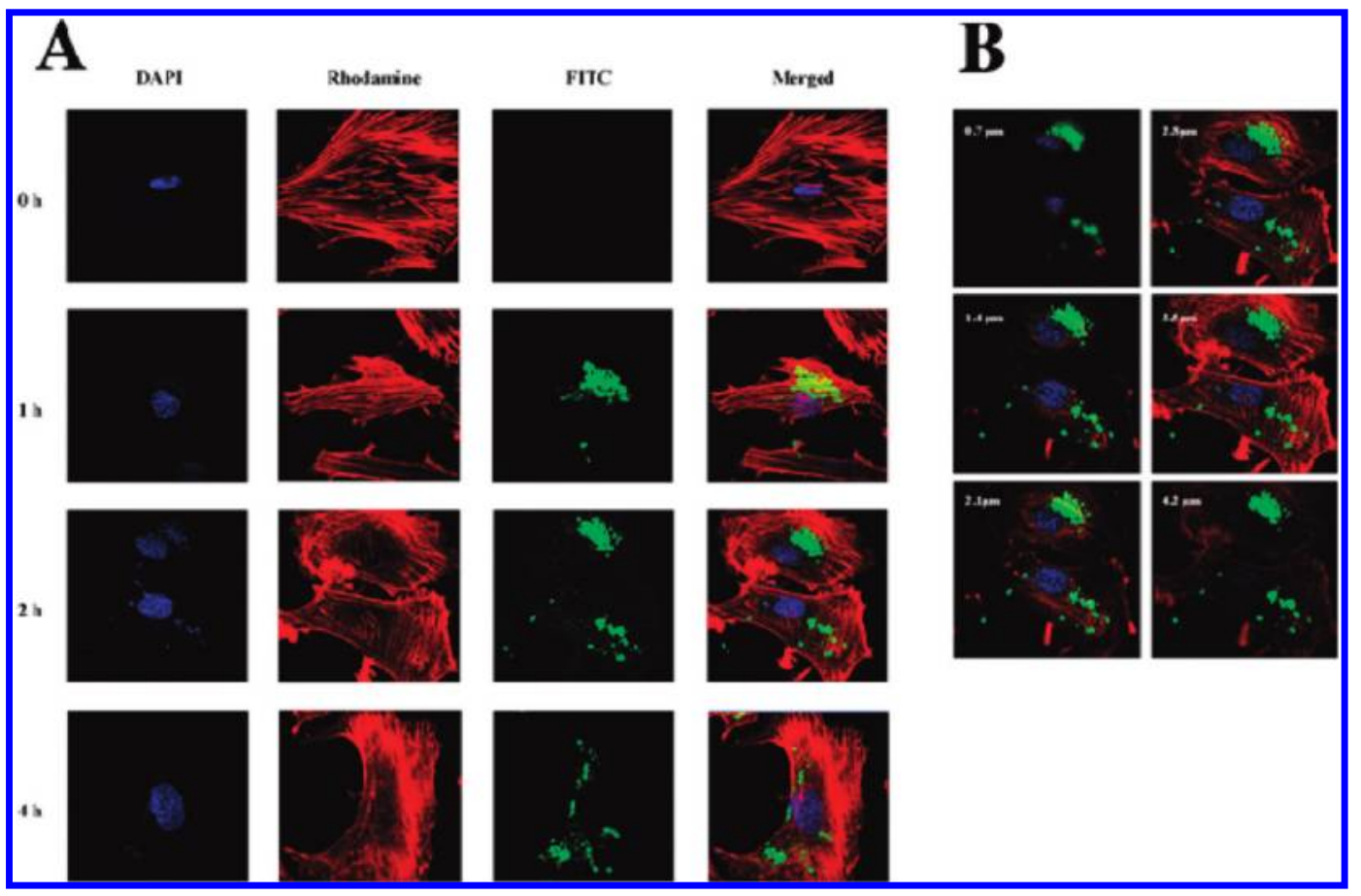

Figure 5. Fluorescence images of VSMCs incubated with magnolol-CHC nanoparticles $(15 \mu \mathrm{g} / \mathrm{mL})$ for $0-4 \mathrm{~h}(\times 1000)($ A). Serial fluorescence $Z$-section images of VSMCs incubated with magnolol-CHC nanoparticles $(15 \mu \mathrm{g} / \mathrm{mL}, 2 \mathrm{~h}$ incubation). The images showed that most nanoparticles were in the cytoplasm of VSMCs (B).

an exceptionally high biological affinity and excellent uptake efficiency to the VSMCs, making a greater potency for inhibiting the growth and migration of the VSMCs. This study suggests that the use of a polysaccharide shell renders a significant improvement in chemical affinity toward the cell membrane, as a result of a potential interaction between amino residues on the membrane surface and carboxyl groups along the CHC shell. ${ }^{46}$

To further quantify the cellular uptake of nanoparticles in cells, the fluorescence intensity in the cells after incubation with the $\mathrm{CHC}$ and magnolol-CHC nanoparticles was determined by flow cytometry. Upon treatment with $50 \mu \mathrm{g} / \mathrm{mL}$ CHC nanoparticles in VSMCs for $4 \mathrm{~h}$, the green fluorescence intensity was elevated in a time-dependent manner (Figure 6A); similar behavior was displayed with a $15 \mu \mathrm{g} / \mathrm{mL}$ dose of the magnolol-CHC nanoparticles (Figure 6B). The proportional amount of the $\mathrm{CHC}$ nanoparticles taken by the cells (M1) was very much the same over time periods of $0.5 \mathrm{~h}, 1 \mathrm{~h}, 2 \mathrm{~h}$ and $4 \mathrm{~h}$ corresponding to $91.7 \%, 93.8 \%, 94.8 \%$ and $96.1 \%$, respectively. The VSMCs also took the magnolol-CHC nanoparticles in an efficient way, showing the accumulated nanoparticles for $0.5 \mathrm{~h}, 1 \mathrm{~h}, 2 \mathrm{~h}$ and $4 \mathrm{~h}$ corresponding to $89.1 \%, 93.1 \%, 93.9 \%$ and $93.5 \%$, respectively (Figure 6C). However, upon analyzing 10,000 events using the $\mathrm{CHC}$ nanoparticles, the fluorescence intensity displayed an increment of about 150 -fold compared with a 32 -fold increment when treated with magnolol-CHC nanoparticles for $4 \mathrm{~h}$. The results proved a faster internalization of the $\mathrm{CHC}$ nanoparticles by VSMCs than that of magnolol-CHC nanoparticles, as illustrated in Figure 6D. The internalization process of the $\mathrm{CHC}$ and magnolol-CHC nanoparticles was further examined using different endocytosis inhibitors. The quantitative analysis of the cellular internalization of the nanoparticles was carried out by flow cytometry, and cellular uptake (\%) on VSMCs was calculated by comparison with that in the absence of inhibitor (as 100\%) for both CHC and magnolol-CHC nanoparticles. Figure $6 \mathrm{E}$ gives several endocytosis inhibitors that were employed to inhibit their specific target pathways. $\mathrm{CHC}$ and magnolol$\mathrm{CHC}$ nanoparticles were individually coincubated with different inhibitors, and inhibitory behavior of the nanoparticle uptake was determined. When treated with CytD, the efficiency of cellular uptake for the magnolol-CHC nanoparticles was reduced to $82 \%$. However, following the treatment of CPZ, the cellular uptake for the $\mathrm{CHC}$ nanoparticles improved to as high as $67 \%$, while it was reduced to $77 \%$ for the magnolol-CHC nanoparticles. For $\mathrm{CHC}$ nanoparticles, the pathway of uptake behavior was found to be associated with clathrin-mediated endocytosis; for the magnolol$\mathrm{CHC}$ nanoparticles, the cellular uptake pathway appeared to come through macropinocytosis and clathrin-mediated endocytosis.

\section{DISCUSSION}

Many core-shell hydrogel nanoparticles have been reported in numerous medical applications in vitro and in vivo. ${ }^{47-49}$ However, it is less extensive in studying the intracellular release with improved therapeutic potency (compared with free drug) for migration inhibition of normal cells, especially using the amphiphilically modified chitosan developed from this lab. The great advantage of this system is clearly demonstrated in the study, and what is more interesting is that such a core-shell nanoparticle drug delivery system was colloidally stable (surfactant free) and exhibited excellent structural integrity without employing cross-linkers, compared with similar reports, especially in the chitosan-related studies in literature. ${ }^{47,49}$ The resulting magnolol-CHC nanoparticles exhibited a negative zeta potential, which is due to the presence of carboxyl groups in the CHC molecules, mainly distributed on the outer surface of the nanoparticles and contributing hydrophilic potential. Increased nanoparticle size 


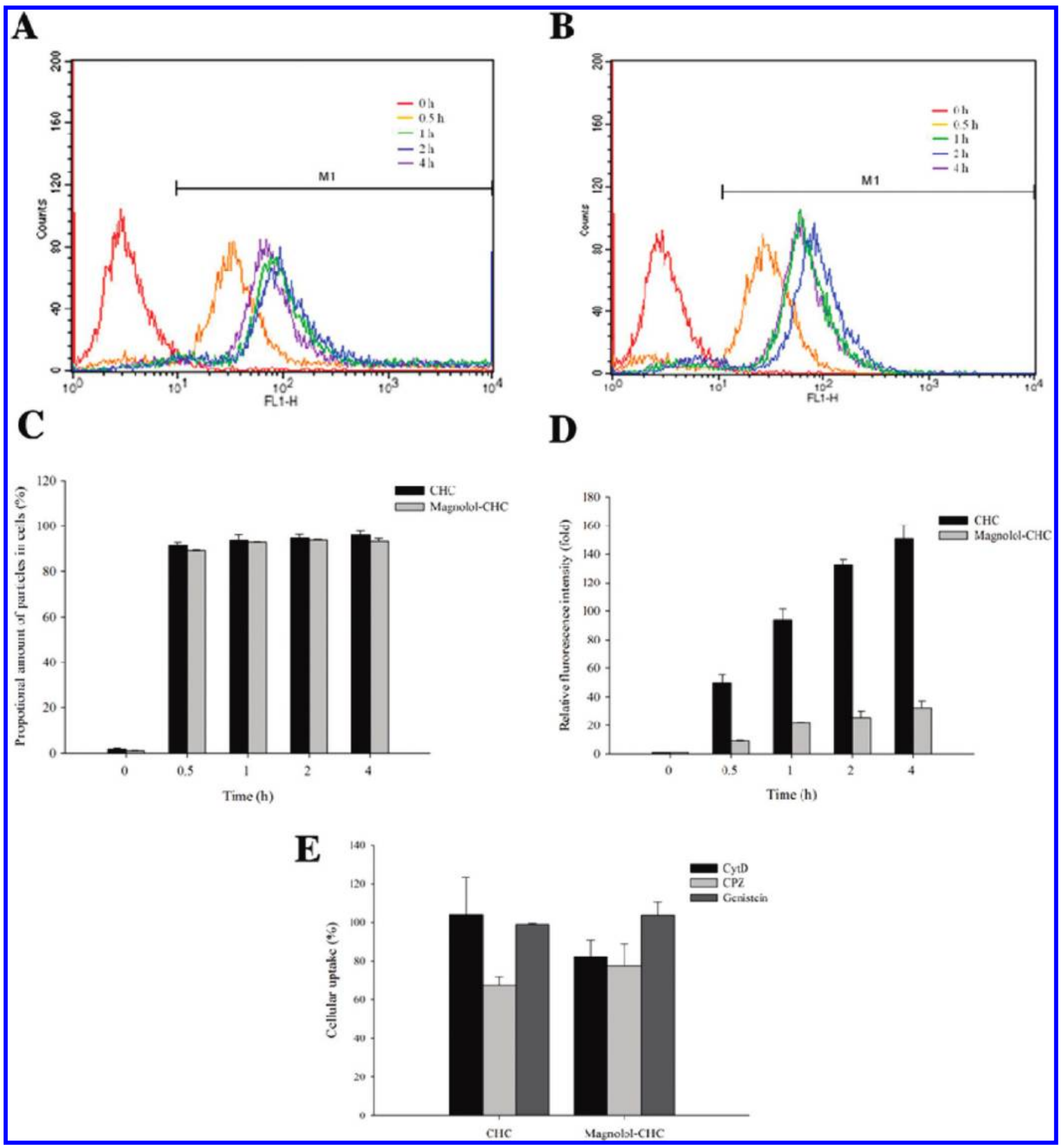

Figure 6. Cell uptake efficiency measured by flow cytometry analysis for CHC (A) and magnolol-CHC nanoparticles (B) in VSMCs. VSMCs were treated with or without magnolol-CHC nanoparticles for $0-4 \mathrm{~h}$. At the end of treatment, the cells were trypsinized and then subjected to flow cytometer analysis. Comparison of proportional amount of particles (C) and relative fluorescence intensity (D) with CHC and magnolol-CHC nanoparticles in VSMCs (M1). Effects of endocytic inhibitors on the internalization of CHC and magnolol-CHC nanoparticles. VSMC cultures were either untreated or pretreated with CPZ (10 $\mu \mathrm{M}$, inhibitor of clathrin-mediated endocytosis), genistein (150 $\mu \mathrm{M}$, inhibitor of caveolae-mediated endocytosis), or CytD $(5 \mu \mathrm{M}$, inhibitor of macropinocytosis) for $30 \mathrm{~min}$. Subsequently, cells were treated with magnolol-CHC nanoparticles $(15 \mu \mathrm{g} / \mathrm{mL})$ for $1 \mathrm{~h}(\mathrm{E})$. Analysis with flow cytometer by 10000 cells was randomly selected for imaging analysis. Each data point is represented as mean $\pm \operatorname{SD}(n=3)$.

with increasing magnolol concentration, from $0.05 \mathrm{mg} / \mathrm{mL}$ to $0.2 \mathrm{mg} / \mathrm{mL}$, Table 1, can result from a considerable increment, by 3 times, of drug payload, from $0.045 \mathrm{mg} / \mathrm{mL}$ to $0.145 \mathrm{mg} / \mathrm{mL}$.
Although the resulting loading efficiency is reduced from $91.6 \%$ to $\sim 80 \%$, enhanced drug payload encourages its potentiality for practical applications. The increase in the core size is proportional 
Table 2. Release Kinetics of Magnolol-CHC Nanoparticles

\begin{tabular}{lclc} 
& \multicolumn{3}{c}{ release kinetics: $r^{2}$} \\
\cline { 2 - 4 } formulation & first order & Higuchi & Korsmeyer-Peppas \\
CHC 0 mg & 0.8166 & 0.9499 & $0.9922(0.1)^{a}$ \\
CHC 0.5 mg & 0.8427 & 0.9792 & $0.9966(0.3)$ \\
CHC 1 mg & 0.7875 & 0.9386 & $0.9822(0.2)$ \\
${ }^{a} n$ in parentheses. & & & \\
\hline
\end{tabular}

to the increase in the final nanoparticle, rendering a reasonable assumption that the shell phase formed may have similar thickness, although it is hard to clearly identify from Figure 1A, upon deposition on the core phase.

The shell acted as an effective barrier for magnolol release. However, an early phase burstlike release of magnolol from the nanoparticles was observed which is probably due to the surface dissolution or desorption of the drug that resided on the outer surface of the shell layer during the preparation procedure, while the same diffusion mechanism dominated a subsequent slower release over a long period of time for those magnolol-CHC nanoparticles. Release profile can be further reduced for the nanoparticles with higher CHC concentration, Table 2, which is primarily a result of increasing shell thickness. To this point, it can be summarized that a sustained release of the magnolol over a much longer releasing period, probably weeks, can be technically achievable to meet diverse therapeutic demands.

Figure $2 \mathrm{~B}$ shows the drug release profiles from the nanoparticles having a $\mathrm{CHC}$ concentration of $0.5 \mathrm{mg} / \mathrm{mL}$ and magnolol of $0.2 \mathrm{mg} / \mathrm{mL}$ because such a combination offered a relatively high drug payload and encapsulation efficiency and was selected as an ideal formulation in forthcoming analysis, in a buffer solution of $\mathrm{pH} 7.4$ at 37 and $4{ }^{\circ} \mathrm{C}$. A temperature-dependent release behavior was observed: higher release rates were obtained at $37{ }^{\circ} \mathrm{C}$, while a lower release rate was detected at $4{ }^{\circ} \mathrm{C}$. For release monitored over a time period of 7 days, the magnolol was $15-30 \%$ higher in amount at $37{ }^{\circ} \mathrm{C}$ than at $4{ }^{\circ} \mathrm{C}$. This temperature-dependent releasing manner is due mainly to the temperature-responsive $\mathrm{CHC}$ shell, since the $\mathrm{CHC}$ molecule possesses hydrophobic groups $\left(-\mathrm{CH}_{3}\right)$ and hydrogen-bondingfavoring groups $\left(-\mathrm{COOH}\right.$, and $\left.-\mathrm{NH}_{2}\right) .{ }^{50} \mathrm{It}$ is well-recognized that increasing ionic strength and/or temperature enhances the hydrophobic effect for chitosan. ${ }^{51}$ On the other hand, increasing temperature decreases hydrogen-bonding interactions in chitosan. ${ }^{50,52}$ Since the temperatures under current study exerted little influence on the sink condition designed for the eluting test, drug diffusion mechanism (having the same releasing patterns) and drug dissolution may be considered constant in the resulting release profiles. Therefore, it is reasonable to assume that, at lower temperature $\left(4{ }^{\circ} \mathrm{C}\right)$, water molecules are presumed to enclose the $\mathrm{CHC}$ chains as being revealed in an earlier report, ${ }^{50}$ where free diffusion of the magnolol may thus be inhibited to a certain extent to across the "enclosed" shell phase of the nanoparticles, resulting in a slower release. However, increasing temperature enhances the vibration and rotation energy of water, weakening intermolecular and intramolecular hydrogen bonds, rendering a further orientation of the water molecules around the polymer chains, ${ }^{50}$ making more favorable in releasing magnolol.

The release kinetics was characterized by fitting the data obtained from the release profiles. The results obtained are presented in Table 2. The model that best fit the release data was selected based on the correlation coefficient value $\left(r^{2}\right)$ of different models, and a diffusion-controlled release as indicated by the Higuchi model can be used to best describe the current drug delivery system. Associated with curve-fitting analysis using the Korsmeyer-Peppas model, giving the $n$ value that is best defined the magnolol release, being a Fickian diffusion from the magnolol-CHC nanoparticles.

Previous investigation reported that apoptosis was not observed in umbilical vein endothelial cells (HUVEC) when magnolol concentration was increased to $100 \mu \mathrm{M}(26.6 \mu \mathrm{g} / \mathrm{mL}){ }^{53}$ These results demonstrated that magnolol would inhibit the growth of smooth muscle cells rather than endothelial cells at concentrations below $20.0 \mu \mathrm{g} / \mathrm{mL}$ (Figure 3B). This confirmed that magnolol with optimal dose could inhibit the proliferation and migration of VSMCs into the arterial intima while exerting no adverse effect on the growth of vascular endothelial cells.

Speaking of restenosis, previous studies have also proved the significant role in VSMCs migration, from the media into the intima, following arterial injury, and it has been widely accepted that blocking the migration of the VSMCs can reduce the neointimal lesion size. ${ }^{54,55}$ To this end, cell migration is considered as another key contributor to restenosis. The reports showed that cells undergoing cell division were only rarely observed in any wells up to $24 \mathrm{~h}^{43}$ As a result, we chose the $24 \mathrm{~h}$ treatment for evaluation of cell migration. The migration of VSMCs treated with $\mathrm{CHC}$ nanoparticles indicated that the $\mathrm{CHC}$ were nontoxic to inhibit the growth and migration of cells, while either free magnolol or magnolol-CHC nanoparticles alone were found to inhibit over a significant extent the migration of VSMCs over $24 \mathrm{~h}$ of treatment. The magnolol-CHC nanoparticles exhibited the greatest inhibitory effect on cell mobility compared to free magnolol at the same dose; one plausible explanation is due to the $15 \mu \mathrm{g} / \mathrm{mL}$ dose for the magnolol-CHC nanoparticles proving less potent in killing the cells but rendering a slow release, including both intercellular and intracellular elution, of the magnolol to deteriorate cell mobility, while the free magnolol was exhausted rapidly after extensive exposure to the cells. The experimental observations indicate that the medical potential of the magnolol-CHC nanoparticles prepared in this work can render them useful as candidates for sustained magnolol delivery for a number of medication purposes, such as anti-restenosis.

The size of the intracellular vesicles containing the endocytosed nanoparticles may give important information regarding the uptake mechanism. ${ }^{56}$ Particle size and shape are two of the important factors for the cellular membrane surface to recognize and eventually internalize through the cellular pathways. ${ }^{57}$ The size of $\mathrm{CHC}$ nanoparticles $(\sim 200 \mathrm{~nm}$ in average) was about 2 -fold smaller than magnolol-CHC nanoparticles ( $\sim 400 \mathrm{~nm}$ in average). The difference of size distribution could affect the uptake ability. CHC nanoparticles were taken by VSMCs much faster than magnolol$\mathrm{CHC}$ nanoparticles. However, smooth muscle cells are also known to exert phagocytosis, generally associated with the uptake of large particles and internalization of particles $>500 \mathrm{~nm} ;{ }^{58,59}$ therefore, magnolol-CHC nanoparticles could be efficiently internalized by VSMCs, still carrying a high enough dose of magnolol, released into cytosol, to effectively inhibit cell migration.

Internalization of particulates occurs through various processes, such as macropinocytosis, clathrin-mediated endocytosis, and caveolae-mediated endocytosis. It is identifiable that these nanoparticles entered VSMCs by the pathways of clathrinmediated endocytosis. Clathrin-mediated endocytosis (for particles in the size range of $\sim 120 \mathrm{~nm}$ ) is the most important mechanism occurring constitutively in all mammalian cells. ${ }^{60}$ For 
the $\mathrm{CHC}$ nanoparticles, the major pathway included clathrinmediated endocytosis. However, for the magnolol-CHC nanopartices, the pathways were mainly associated with macropinocytosis, together with clathrin-mediated endocytosis. Reports showed that the clathrin-mediated endocytosis pathway is initiated by a specific ligand-receptor interaction on the extracellular surface. Upon entry, internalized nanoparticles are generally entrapped in the intracellular vesicles (i.e., endosomes). Certain internalization pathways such as clathrin-mediated endocytosis may lead to a complete degradation of macromolecular carriers at the later lysosomal stage. ${ }^{61,62}$ Both efficient endocytic mechanisms permitted an intracellular release of magnolol into the cells to effectively inhibit the migration and growth of the VSMCs.

\section{CONCLUSIONS}

This study describes a unique design and synthesis of magnolol$\mathrm{CHC}$ core-shell nanosystem for drug delivery purpose. Experimental outcomes have demonstrated outstanding cytocompatibility of the magnolol-CHC nanoparticles with VSMCs and the capability of providing a sustained intracellular release of magnolol after significant cellular internalization over a short period of contact. Magnolol-CHC nanoparticles reduced the cell viability of VSMCs in vitro more effectively than the free drug, where an intracellular drug release should play a critical role. Confocal laser scanning microscopy confirmed the efficient uptake of magnolol-CHC nanoparticles, even though the magnolol-CHC nanoparticles are relatively large in dimension, $235-420 \mathrm{~nm}$. Furthermore, magnolol-CHC nanoparticles could exert a strong antimetastatic effect onto VSMCs to inhibit significantly the cell mobility. These findings support the rationale for the design of a magnolol-CHC core-shell hydrogel nanosystem with improved biocompatible and intracellular therapeutic features. Besides the diverse medical advantages of the herbal drug, magnolol, a successful manipulation of controlled cytotoxicity via intracellular magnolol delivery envisions its potential nanotherapeutic medications for a vast number of practical needs. A subsequent in vivo study using the current delivery system is under investigation and will be reported separately.

\section{AUTHOR INFORMATION}

\section{Corresponding Author}

${ }^{*}$ National Chiao Tung University, Nano-Bioengineering Lab, Department of Materials Science and Engineering, 1001 Ta-Hseuh Road, Hsinchu 30049, Taiwan. Tel: +886-5712121 ext 55391. Fax: +886-3-5724727. E-mail: deanmo_liu@yahoo.ca.

\section{ACKNOWLEDGMENT}

The project is supported by the National Chiao Tung University, Taiwan, under Contract No. NSC 99-2113-M-009-013-MY2.

\section{ABBREVIATIONS USED}

magnolol-CHC nanoparticles, magnolol-loaded core-shell hydrogel nanoparticle; PVP, polyvinylpyrrolidone; $\mathrm{CHC}$, amphiphilic carbomethyl-hexanol chitosan; HPLC, high-performance liquid chromatography; VSMCs, vascular smooth muscle cells; FITC, fluorescein isothiocyanate; FITC-CHC nanoparticles, FITC labeled CHC nanoparticles; FITC-magnolol-CHC nanoparticles, FITC labeled magnolol-CHC nanoparticles; MTT, 3-(4, 5-dimethylthiazol-2-yl)-2,5-diphenyltetrazolium bromide; CytD, cytochalasin D; CPZ, chlorpromazine; DAPI, 4',6-diamidino-2phenylindole

\section{REFERENCES}

(1) Singh, S. Nanomedicine-nanoscale drugs and delivery systems. J. Nanosci. Nanotechnol. 2010, 10 (12), 7906-18.

(2) Cheng, C.; Wei, H.; Shi, B. X.; Cheng, H.; Li, C.; Gu, Z. W.; Cheng, S. X.; Zhang, X. Z.; Zhuo, R. X. Biotinylated thermoresponsive micelle self-assembled from double-hydrophilic block copolymer for drug delivery and tumor target. Biomaterials 2008, 29 (4), 497-505.

(3) Wang, Z.; Ho, P. C. Self-assembled core-shell vascular-targeted nanocapsules for temporal antivasculature and anticancer activities. Small 2010, 6 (22), 2576-83.

(4) Powell, T. J.; Palath, N.; DeRome, M. E.; Tang, J.; Jacobs, A.; Boyd, J. G. Synthetic nanoparticle vaccines produced by layer-by-layer assembly of artificial biofilms induce potent protective T-cell and antibody responses in vivo. Vaccine 2011, 29 (3), 558-69.

(5) Lammers, T.; Kiessling, F.; Hennink, W. E.; Storm, G. Nanotheranostics and image-guided drug delivery: current concepts and future directions. Mol. Pharmaceutics 2010, 7 (6), 1899-912.

(6) Oghabian, M. A.; Farahbakhsh, N. M. Potential use of nanoparticle based contrast agents in MRI: a molecular imaging perspective. L. Biomed. Nanotechnol. 2010, 6 (3), 203-13.

(7) Chen, Y. H.; Lin, F. Y.; Liu, P. L.; Huang, Y. T.; Chiu, J. H.; Chang, Y. C.; Man, K. M.; Hong, C. Y.; Ho, Y. Y.; Lai, M. T. Antioxidative and hepatoprotective effects of magnolol on acetaminophen-induced liver damage in rats. Arch. Pharm. Res. 2009, 32 (2), 221-8.

(8) Shen, J. L.; Man, K. M.; Huang, P. H.; Chen, W. C.; Chen, D. C.; Cheng, Y. W.; Liu, P. L.; Chou, M. C.; Chen, Y. H. Honokiol and magnolol as multifunctional antioxidative molecules for dermatologic disorders. Molecules 2010, 15 (9), 6452-65.

(9) Chen, H. Y.; Hung, Y. C.; Lee, E. J.; Chen, T. Y.; Chuang, I. C.; $\mathrm{Wu}, \mathrm{T}$. S. The protective efficacy of magnolol in hind limb ischemiareperfusion injury. Phvtomedicine 2009, 16 (10), 976-81.

(10) Lin, Y. R.; Chen, H. H.; Lin, Y. C.; Ko, C. H.; Chan, M. H. Antinociceptive actions of honokiol and magnolol on glutamatergic and inflammatory pain. L.Biomed. Sci. 2009, 16, 94.

(11) Kuo, D. H.; Lai, Y. S.; Lo, C. Y.; Cheng, A. C.; Wu, H.; Pan, M. H. Inhibitory effect of magnolol on TPA-induced skin inflammation and tumor promotion in mice. J. Agric. Food Chem. 2010, 58 (9), 5777-83.

(12) Chen, L. C.; Liu, Y. C.; Liang, Y. C.; Ho, Y. S.; Lee, W. S. Magnolol inhibits human glioblastoma cell proliferation through upregulation of p21/Cip1. L. Agric. Food Chem. 2009, 57 (16), 7331-7.

(13) Huang, S. H.; Chen, Y.; Tung, P. Y.; Wu, J. C.; Chen, K. H.; Wu, J. M.; Wang, S. M. Mechanisms for the magnolol-induced cell death of CGTH W-2 thyroid carcinoma cells. J. Cell. Biochem. 2007, 101 (4), 1011-22.

(14) Xu, Q.; Yi, L. T.; Pan, Y.; Wang, X.; Li, Y. C.; Li, J. M.; Wang, C. P.; Kong, L. D. Antidepressant-like effects of the mixture of honokiol and magnolol from the barks of Magnolia officinalis in stressed rodents. Prog. Neuro Psychopharmacol. Biol. Psychiatry 2008, 32 (3), 715-25.

(15) Wu, C. H.; Chen, C. W.; Chen, H. C.; Chang, W. C.; Shu, M. J.; Hung, J. S. Elucidating the inhibitory mechanisms of magnolol on rat smooth muscle cell proliferation. I. Pharmacol. Sci. 2005, 99 (4), 392-9.

(16) Chen, J. H.; Wu, C. C.; Hsiao, G.; Yen, M. H. Magnolol induces apoptosis in vascular smooth muscle. Naunyn Schmiedeberg's Arch. Pharmacol. 2003, 368 (2), 127-33.

(17) Kim, H. M.; Bae, S. J.; Kim, D. W.; Kim, B. K.; Lee, S. B.; Lee, U. S.; Kim, C. H.; Moon, S. K. Inhibitory role of magnolol on proliferative capacity and matrix metalloproteinase- 9 expression in TNF-alpha-induced vascular smooth muscle cells. Int. Immunopharmacol. 2007, 7 (8), 1083-91.

(18) Yin, H. Q.; Je, Y. T.; Kim, Y. C.; Shin, Y. K.; Sung, S.; Lee, K.; Jeong, G. S.; Lee, B. H. Magnolia officinalis reverses alcoholic fatty liver 
by inhibiting the maturation of sterol regulatory element-binding protein-1c. J. Pharmacol. Sci. 2009, 109 (4), 486-95.

(19) Lee, D. H.; Szczepanski, M. J.; Lee, Y. J. Magnolol induces apoptosis via inhibiting the EGFR/PI3K/Akt signaling pathway in human prostate cancer cells. I. Cell. Biochem. 2009, 106 (6), 1113-22.

(20) Li, M. H.; Kothandan, G.; Cho, S. J.; Huong, P. T.; Nan, Y. H.; Lee, K. Y.; Shin, S. Y.; Yea, S. S.; Jeon, Y. J. Magnolol Inhibits LPSinduced NF-kappaB/Rel Activation by Blocking p38 Kinase in Murine Macrophages. Korean I. Phvsiol. Pharmacol. 2010, 14 (6), 353-8.

(21) Hwang, E. S.; Park, K. K. Magnolol suppresses metastasis via inhibition of invasion, migration, and matrix metalloproteinase-2/-9 activities in PC-3 human prostate carcinoma cells. Biosci., Biotechnol., Biochem. 2010, 74 (5), 961-7.

(22) Aggarwal, B. B.; Sethi, G.; Ahn, K. S.; Sandur, S. K.; Pandey, M. K.; Kunnumakkara, A. B.; Sung, B.; Ichikawa, H. Targeting signaltransducer-and-activator-of-transcription-3 for prevention and therapy of cancer: modern target but ancient solution. Ann. N.Y. Acad. Sci. 2006, 1091, 151-69.

(23) Regan, C. P.; Adam, P. J.; Madsen, C. S.; Owens, G. K. Molecular mechanisms of decreased smooth muscle differentiation marker expression after vascular injury. L. Clin. Invest. 2000, 106 (9), 1139-47.

(24) Pollman, M. J.; Hall, J. L.; Gibbons, G. H. Determinants of vascular smooth muscle cell apoptosis after balloon angioplasty injury. Influence of redox state and cell phenotype. Circ. Res. 1999, 84 (1), $113-21$.

(25) Szocs, K.; Lassegue, B.; Sorescu, D.; Hilenski, L. L.; Valppu, L.; Couse, T. L.; Wilcox, J. N.; Quinn, M. T.; Lambeth, J. D.; Griendling, K. K. Upregulation of Nox-based $\mathrm{NAD}(\mathrm{P}) \mathrm{H}$ oxidases in restenosis after carotid injury. Arterioscler. Thromb. Vasc. Biol. 2002, 22 (1), $21-7$.

(26) Lo, Y. C.; Teng, C. M.; Chen, C. F.; Chen, C. C.; Hong, C. Y. Magnolol and honokiol isolated from Magnolia officinalis protect rat heart mitochondria against lipid peroxidation. Biochem. Pharmacol. 1994, 47 (3), 549-53.

(27) He, S.; Zhang, Z.; Xu, F.; Zhang, S.; Lei, Z. Micronization of magnolia bark extract with enhanced dissolution behavior by rapid expansion of supercritical solution. Chem. Pharm. Bull. (Tokyo) 2010, 58 (2), 154-9.

(28) Chen, C. Y.-C.; Wu, C.-H. Magnolol encapsulated by liposome in inhibiting smooth muscle cell proliferation. J. Chin. Chem. Soc. 2008, 55, 517-521.

(29) Hans, M. L.; Lowman, A. M. Biodegradable nanoparticles for drug delivery and targeting. Curr. Opin. Solid State Mater. Sci. 2002, 6 (4), 319-327.

(30) Woodle, M. C. Sterically stabilized liposome therapeutics. Adv. Drug Deliverv Rev. 1995, 16 (2-3), 249-265.

(31) Chen, M. C.; Tsai, H. W.; Liu, C. T.; Peng, S. F.; Lai, W. Y.; Chen, S. J.; Chang, Y.; Sung, H. W. A nanoscale drug-entrapment strategy for hydrogel-based systems for the delivery of poorly soluble drugs. Biomaterials 2009, 30 (11), 2102-11.

(32) Pluta, J.; Karolewicz, B. Hydrogels: properties and application in the technology of drug form. II. Possibilities of use of hydrogels as active substance carriers. Polim. Med. 2004, 34 (3), 63-81.

(33) Khutoryanskiy, V. V. Hydrogen-bonded interpolymer complexes as materials for pharmaceutical applications. Int. J. Pharm. 2007, 334 (1-2), 15-26.

(34) Hamidi, M.; Azadi, A.; Rafiei, P. Hydrogel nanoparticles in drug delivery. Adv. Drug Deliverv Rev. 2008, 60 (15), 1638-1649.

(35) Huo, M.; Zhang, Y.; Zhou, J.; Zou, A.; Yu, D.; Wu, Y.; Li, J.; Li, H. Synthesis and characterization of low-toxic amphiphilic chitosan derivatives and their application as micelle carrier for antitumor drug. Int. J. Pharm. 2010, 394 (1-2), 162-73.

(36) Liu, K.-H.; Chen, S.-Y.; Liu, D.-M.; Liu, T.-Y. Self-Assembled Hollow Nanocapsule from Amphiphatic Carboxymethyl-hexanoyl Chitosan as Drug Carrier. Macromolecules 2008, 41 (17), 6511-6516.

(37) Liu, T. Y.; Chen, S. Y.; Lin, Y. L.; Liu, D. M. Synthesis and characterization of amphiphatic carboxymethyl-hexanoyl chitosan hydrogel: water-retention ability and drug encapsulation. Langmuir 2006 22 (23), 9740-5.
(38) Lamaze, C.; Schmid, S. L. The emergence of clathrin-independent pinocytic pathways. Curr. Opin. Cell Biol. 1995, 7 (4), 573-580.

(39) Wang, L. H.; Rothberg, K. G.; Anderson, R. G. Mis-assembly of clathrin lattices on endosomes reveals a regulatory switch for coated pit formation. L. Cell Biol. 1993, 123 (5), 1107-17.

(40) Chang, M.; Chou, J.-C.; Chen, C.-P.; Liu, B. R.; Lee, H.-J. Noncovalent protein transduction in plant cells by macropinocytosis. New Phvtol. 2007, 174 (1), 46-56.

(41) Niwa, T.; Takeuchi, H.; Hino, T.; Kunou, N.; Kawashima, Y. Preparations of biodegradable nanospheres of water-soluble and insoluble drugs with D,L-lactide/glycolide copolymer by a novel spontaneous emulsification solvent diffusion method, and the drug release behavior. I. Controlled Release 1993, 25 (1-2), 89-98.

(42) Costa, P.; Sousa Lobo, J. M. Modeling and comparison of dissolution profiles. Eur. I. Pharm. Sci. 2001, 13 (2), 123-133.

(43) Murugesan, G.; Chisolm, G. M.; Fox, P. L. Oxidized low density lipoprotein inhibits the migration of aortic endothelial cells in vitro. L. Cell Biol. 1993, 120 (4), 1011-9.

(44) Shen, K. H.; Hung, S. H.; Yin, L. T.; Huang, C. S.; Chao, C. H.; Liu, C. L.; Shih, Y. W. Acacetin, a flavonoid, inhibits the invasion and migration of human prostate cancer DU145 cells via inactivation of the p38 MAPK signaling pathway. Mol. Cell. Biochem. 2010, 333 (1-2), 279-91.

(45) Sekikawa, H.; Nakano, M.; Arita, T. Inhibitory Effect of Polyvinylpyrrolidone on the Crystallization of Drugs. Chem. Pharm. Bull. 1978, 26 (1), 118-26.

(46) Zhou, Y.; She, S.; Zhang, L.; Lu, Q. Determination of Proteins at Nanogram Levels Using the Resonance Light Scattering Technique with a Novel PVAK Nanoparticle. Microchim. Acta 2005, 149 (1-2), 151-6.

(47) Zhang, W.; Gilstrap, K.; Wu, L.; K, C. R.; Moss, M. A.; Wang, Q.; Lu, X.; He, X. Synthesis and characterization of thermally responsive Pluronic F127-chitosan nanocapsules for controlled release and intracellular delivery of small molecules. ACS Nano 2010, 4 (11), 6747-59.

(48) Saremi, S.; Atyabi, F.; Akhlaghi, S. P.; Ostad, S. N.; Dinarvand, R. Thiolated chitosan nanoparticles for enhancing oral absorption of docetaxel: preparation, in vitro and ex vivo evaluation. Int. J. Nanomed. 2011, 6, 119-28.

(49) Shu, S.; Zhang, X.; Wu, Z.; Wang, Z.; Li, C. Gradient crosslinked biodegradable polyelectrolyte nanocapsules for intracellular protein drug delivery. Biomaterials 2010, 31 (23), 6039-49.

(50) Cho, J.; Heuzey, M.-C.; Bégin, A.; Carreau, P. J. Physical Gelation of Chitosan in the Presence of $\beta$-Glycerophosphate: The Effect of Temperature. Biomacromolecules 2005, 6 (6), 3267-75.

(51) Desbrières, J.; Martinez, C.; Rinaudo, M. Hydrophobic derivatives of chitosan: Characterization and rheological behaviour. Int. J. Biol. Macromol. 1996, 19 (1), 21-8.

(52) Kasaai, M. R.; Charlet, G.; Arul, J. Master curve for concentration dependence of semi-dilute solution viscosity of chitosan homologues: the Martin equation. Food Res Int 2000, 33 (1), 63-7.

(53) Lin, S. Y.; Liu, J. D.; Chang, H. C.; Yeh, S. D.; Lin, C. H.; Lee, W. S. Magnolol suppresses proliferation of cultured human colon and liver cancer cells by inhibiting DNA synthesis and activating apoptosis. I. Cell. Biochem. 2002, 84 (3), 532-44.

(54) Rutherford, C.; Martin, W.; Salame, M.; Carrier, M.; Anggard, E.; Ferns, G. Substantial inhibition of neo-intimal response to balloon injury in the rat carotid artery using a combination of antibodies to platelet-derived growth factor-BB and basic fibroblast growth factor. Atherosclerosis 1997, 130 (1-2), 45-51.

(55) Slepian, M. J.; Massia, S. P.; Dehdashti, B.; Fritz, A.; Whitesell, L. Beta3-integrins rather than beta1-integrins dominate integrin-matrix interactions involved in postinjury smooth muscle cell migration. Circulation 1998, 97 (18), 1818-27.

(56) Iversen, T.-G.; Skotland, T.; Sandvig, K. Endocytosis and intracellular transport of nanoparticles: Present knowledge and need for future studies. Nano Todav 2011, 6 (2), 176-85.

(57) Chithrani, B. D.; Chan, W. C. W. Elucidating the Mechanism of Cellular Uptake and Removal of Protein-Coated Gold Nanoparticles of Different Sizes and Shapes. Nano Lett. 2007, 7 (6), 1542-50. 
(58) Bennett, M. R.; Gibson, D. F.; Schwartz, S. M.; Tait, J. F. Binding and phagocytosis of apoptotic vascular smooth muscle cells is mediated in part by exposure of phosphatidylserine. Circ. Res. 1995, 77 (6), 1136-42.

(59) Rupper, A.; Cardelli, J. Regulation of phagocytosis and endophagosomal trafficking pathways in Dictyostelium discoideum. Biochim. Biophvs. Acta 2001, 1525 (3), 205-16.

(60) Brodsky, F. M.; Chen, C. Y.; Knuehl, C.; Towler, M. C.; Wakeham, D. E. Biological basket weaving: formation and function of clathrin-coated vesicles. Annu. Rev. Cell Dev. Biol. 2001, 17, 517-68.

(61) Watson, P.; Jones, A. T.; Stephens, D. J. Intracellular trafficking pathways and drug delivery: fluorescence imaging of living and fixed cells. Adv. Drug Deliverv Rev. 2005, 57 (1), 43-61.

(62) Nam, H. Y.; Kwon, S. M.; Chung, H.; Lee, S.-Y.; Kwon, S.-H.; Jeon, H.; Kim, Y.; Park, J. H.; Kim, J.; Her, S.; Oh, Y.-K.; Kwon, I. C.; Kim, K.; Jeong, S. Y. Cellular uptake mechanism and intracellular fate of hydrophobically modified glycol chitosan nanoparticles. J. Controlled Release 2009, 135 (3), 259-67. 